\title{
EXAFS AND XANES ANALYSIS OF PLUTONIUM AND CERIUM EDGES FROM TITANATE CERAMICS FOR FISSILE MATERIALS DISPOSAL
}

\author{
J. A. Fortner, A. J. Kropf, A. J. Bakel, M. C. Hash, S. B. Aase, E. C. Buck, \\ and D. B. Chamberlain \\ Chemical Technology Division \\ ARGONNE NATIONAL LABORATORY \\ 9700 South Cass Avenue \\ Argonne, IL 60439-4837

The submitted manuscript has been authored
by a contractor of the U.S. Government under
contract No. W-31-108-ENG-38. Accordingly,
the U.S. Government retains a nonexclusive,
royalty-free license to publish or reproduce the
published form of this contribution, or allow
others to do so, for U.S. Government
purposes.

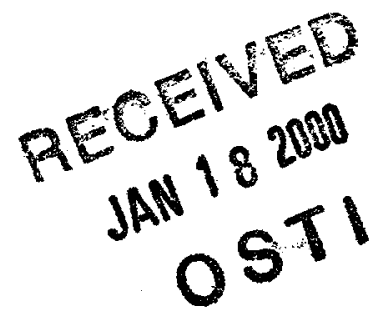

For presentation at

Scientific Basis for Nuclear Waste Management XXII

Materials Research Society 1999 Fall Meeting

November 30 to December 4, 1999

Boston, Massachusetts

This work was supported by the U. S. Department of Energy Office of Fissile Materials Disposition under Contract no. W-31-109-Eng-38. Use of the Advanced Photon Source was supported by the U.S. Department of Energy, Basic Energy Sciences, Office of Energy Research (DOE-BES-OER), under Contract no. W-31-109-Eng-38. The MRCAT beamlines are supported by the member institutions and the U.S. DOE-BES-OER under contracts DE-FG02-94ER45525 and DE-FG02-96ER45589. 


\section{DISCLAIMER}

This report was prepared as an account of work sponsored by an agency of the United States Government. Neither the United States Government nor any agency thereof, nor any of their employees, make any warranty, express or implied, or assumes any legal liability or responsibility for the accuracy, completeness, or usefulness of any information, apparatus, product, or process disclosed, or represents that its use would not infringe privately owned rights. Reference herein to any specific commercial product, process, or service by trade name, tradernark, manufacturer, or otherwise does not necessarily constitute or imply its endorsement, recommendation, or favoring by the United States Government or any agency thereof. The views and opinions of authors expressed herein do not necessarily state or reflect those of the United States Government or any agency thereof. 


\section{DISCLAIMER}

Portions of this document may be illegible in electronic image products. Images are produced from the best available original document. 


\title{
EXAFS AND XANES ANALYSIS OF PLUTONIUM AND CERIUM EDGES FROM TITANATE CERAMICS FOR FISSILE MATERIALS DISPOSAL
}

\author{
J. A. Fortner, A. J. Kropf. A. J. Bakel, M. C. Hash, S. B. Aase, E. C. Buck, and D. B. \\ Chamberlain \\ Argonne National Laboratory. Chemical Technology Division, Argonne, IL 60439
}

We report $\mathrm{x}$-ray absorption near edge structure (XANES) and extended $\mathrm{x}$-ray absorption fine structure (EXAFS) spectra from the plutonium $L_{\text {III }}$ edge and XANES from the cerium $L_{11}$ edge in prototype titanate ceramic hosts. The titanate ceramics studied are based upon the hafnium-pyrochlore and zirconolite mineral structures and will serve as an immobilization host for surplus fissile materials, containing as much as 10 weight $\%$ fissile plutonium and 20 weight $\%$ (natural or depleted) uranium. Three ceramic formulations were studied: one employed cerium as a "surrogate" element, replacing both plutonium and uranium in the ceramic matrix, another formulation contained plutonium in a "baseline" ceramic formulation, and a third contained plutonium in a formulation representing a high-impurity plutonium stream. The cerium XANES from the surrogate ceramic clearly indicates a mixed III-IV oxidation state for the cerium. In contrast, XANES analysis of the two plutonium-bearing ceramics shows that the plutonium is present almost entirely as $\mathrm{Pu}(\mathrm{IV})$ and occupies the calcium site in the zirconolite and pyrochlore phases. The plutonium EXAFS real-space structure shows a strong second-shell peak, clearly distinct from that of $\mathrm{PuO}_{2}$, with remarkably little difference in the plutonium crystal chemistry indicated between the baseline and high-impurity formulations.

We demonstrate use of XANES and EXAFS for characterizing the oxidation state and coordination environment of plutonium and cerium (as a plutonium "surrogate") in prototype samples of the immobilization ceramic. The chemical formulations of the baseline ("A0") and high-impurity ("A9") titanate ceramics studied are provided in Table 1 . The surrogate ceramic had a chemical composition similar to $\mathrm{A} 0$, with cerium substituted for plutonium and uranium on a molar basis. The major phases in these ceramics are pyrochlore [ $\mathrm{A}_{2} \mathrm{Ti}_{2} \mathrm{O} 7$ ], zirconolite $\left[\mathrm{ABTi}_{2} \mathrm{O}_{7}\right]$, Hf-bearing rutile $\left(\mathrm{TiO}_{2}\right)$, and brannerite $\left[\mathrm{BTi}_{2} \mathrm{O}_{6}\right]$, where $\mathrm{A}=\mathrm{Ca}$, actinides $(\mathrm{ACT}$ ), and rare earth elements (REE), and $\mathrm{B}=\mathrm{ACT}, \mathrm{REE}, \mathrm{Zr}$, and Hf. Additional minor phases may occur depending on waste loading; these include uranium oxides and glassy phases. The glassy phases (and rutile) fill interstices between the major phases [1]. Both $\mathrm{Hf}$ and $\mathrm{Gd}$ are added to the ceramic formulation as neutron absorbers in order to satisfy a defense-in-depth concept for the waste form. The A0 and A9 samples were both calcined in air (stagnant, $750^{\circ} \mathrm{C}$ ) and sintered in flowing argon $\left(1350^{\circ} \mathrm{C}\right)$. The cerium surrogate sample was calcined and sintered in stagnant air $\left(750^{\circ} \mathrm{C}\right.$ and $1350^{\circ} \mathrm{C}$, respectively).

The EXAFS measurements were made at the Advanced Photon Source (APS) using the Materials Research Collaborative Access Team (MRCAT) undulator beam line. Measurements were made in fluorescence mode with the incident intensity ionization chamber optimized for maximum current with linear response $\left(\sim 10^{10}\right.$ photons detected $\left./ \mathrm{sec}\right)$. The fluorescence ionization chamber was filled with xenon gas and produced a signal of $\sim 10^{8}$ photons/sec above the absorption edge. A double crystal Si (111) monochromator with resolution of better than $4 \mathrm{eV}$ at $20 \mathrm{keV}$ was used in conjunction with a Pt-coated mirror to minimize the presence of harmonics. The counting time for the data ranged from 2 to 8 seconds per point in the EXAFS region. The experimental spectra were fitted using the program $F E F I T$ from the University of Washington package, and $F E F F$, version 8.00 , to generate the scattering paths [2]. 
Table 1. Ceramic compositions in weight percent.

\begin{tabular}{lrrc}
\hline Compound & \multicolumn{3}{c}{ Specimen Type } \\
& \multicolumn{1}{c}{ A 0} & \multicolumn{1}{c}{ surrogate } \\
\hline $\mathrm{CaO}$ & 9.95 & 9.44 & 14.52 \\
$\mathrm{TiO}_{2}$ & 35.87 & 34.04 & 39.76 \\
$\mathrm{HfO}_{2}$ & 10.65 & 10.11 & 11.82 \\
$\mathrm{Gd}_{2} \mathrm{O}_{3}$ & 7.95 & 7.54 & 8.80 \\
$\mathrm{UO}_{2}$ & 23.69 & 22.48 & - \\
$\mathrm{PuO}_{2}$ & 11.89 & 11.28 & - \\
$\mathrm{CeO}_{2}$ & - & - & 25.10 \\
$\mathrm{Al}_{2} \mathrm{O}_{3}$ & - & 0.50 & - \\
$\mathrm{MgO}_{2}$ & - & 0.44 & - \\
$\mathrm{CaCl}_{2}$ & - & 0.66 & - \\
$\mathrm{Ga}_{2} \mathrm{O}_{2}$ & - & 0.57 & - \\
$\mathrm{Fe}_{2} \mathrm{O}_{3}$ & - & 0.15 & - \\
$\mathrm{Cr}_{2} \mathrm{O}_{3}$ & - & 0.08 & - \\
$\mathrm{NiO} \mathrm{CaF}_{2}$ & - & 0.13 & - \\
$\mathrm{CaF}_{2}$ & - & 0.44 & - \\
$\mathrm{K}_{2} \mathrm{O}$ & - & 0.32 & - \\
$\mathrm{Na}_{2} \mathrm{O}$ & - & 0.14 & - \\
$\mathrm{MoO}_{2}$ & - & 0.28 & - \\
$\mathrm{SiO}_{2}$ & - & 0.46 & - \\
$\mathrm{Ta}_{2} \mathrm{O}_{5}$ & - & 0.19 & - \\
$\mathrm{B}_{2} \mathrm{O}_{3}$ & - & 0.17 & - \\
$\mathrm{WO}_{2}$ & - & 0.49 & - \\
$\mathrm{ZnO}$ & - & 0.07 & - \\
\hline & & & \\
\hline
\end{tabular}

Standards for cerium were $\mathrm{Ce}(\mathrm{III}) \mathrm{PO}_{4}$ and $\mathrm{Ce}(\mathrm{IV}) \mathrm{O}_{2}$, while high-fired $\mathrm{PuO}_{2}$ served as a plutonium standard. The $\mathrm{Ce}-\mathrm{L}_{\mathrm{II}} \mathrm{XANES}$ from the cerium surrogate ceramic was clearly located between the $\mathrm{Ce}$ (III) and $\mathrm{Ce}$ (IV) standards (Figure 1). Fitting the edge structure with a linear combination of spectra from the $\mathrm{Ce}$ (III) and Ce(IV) standards yielded an oxidation state of 3.7, consistent with earlier studies on cerium-loaded Synroc [3]. Remarkably, the entire edge structure could be reasonably fit, including the edge position, the location and relative heights of the split peaks in the $\mathrm{L}_{\text {II }}$ spectrum, and the relative height of the continuum that occurs after the white line (Figure 2).

The near-edge structure (XANES) contains information on the formal oxidation state of the absorbing species. The XANES was fitted by a methodology described elsewhere that uses the sum of a Lorentzian and a hyperbolic tangent function [4]. The analysis of the plutonium edge in the prototype ceramics (Figure 3) demonstrates that it is almost entirely in the Pu(IV) oxidation state. The XANES was nearly identical for the $\mathrm{A} 0$ and $\mathrm{A} 9$ samples, both having the edge position and qualitative edge structure much like those of the $\mathrm{PuO}_{2}$ standard [4,5]. 


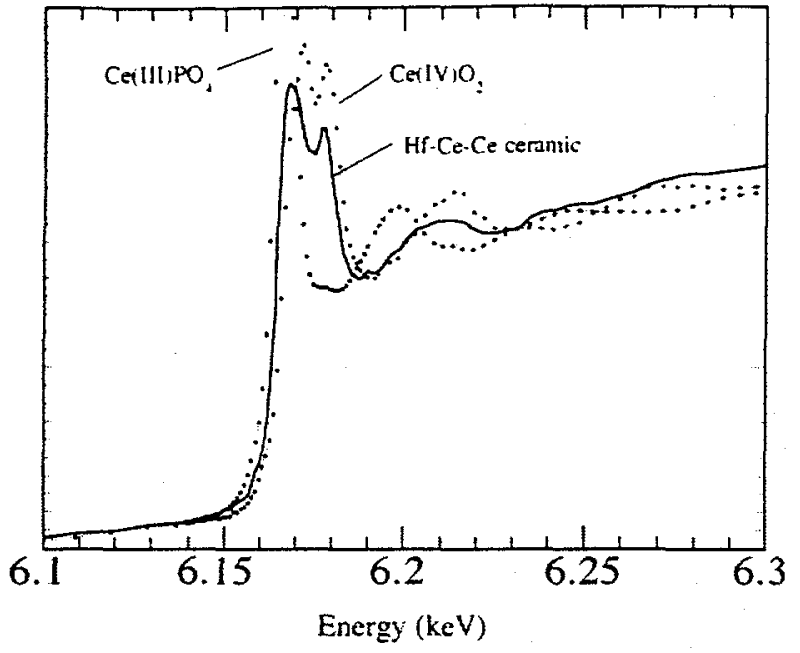

Figure 1. The cerium in the surrogate ceramic (solid line) has a mixed oxidation state, as illustrated by this comparison with XANES standards (lines with points). For clarity, the intense white line of the Ce (III) standard has been cut off in the figure.

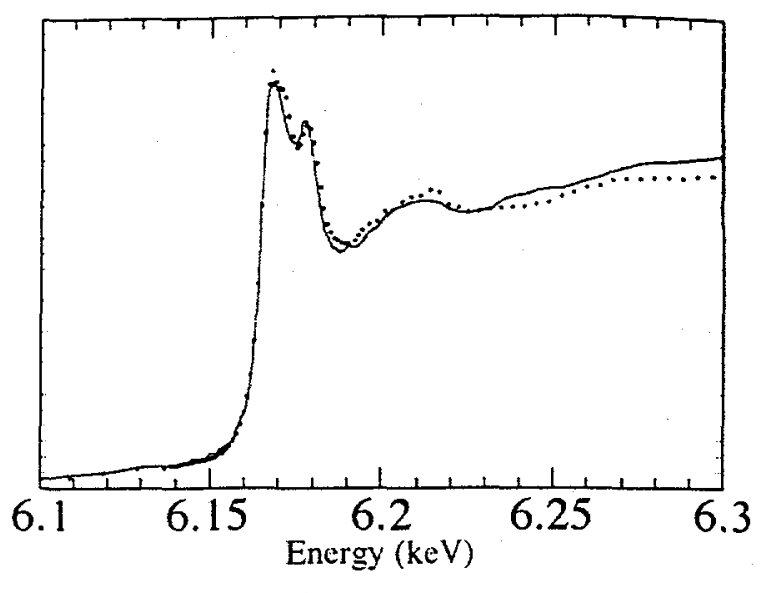

Figure 2. The cerium XANES from the ceramic (solid line) was fitted with a linear combination of $70 \% \mathrm{Ce}(\mathrm{IV}) \mathrm{O}_{2}$ and $30 \%$ $\mathrm{Ce}(\mathrm{III}) \mathrm{PO}_{4}$ standards (dotted line).

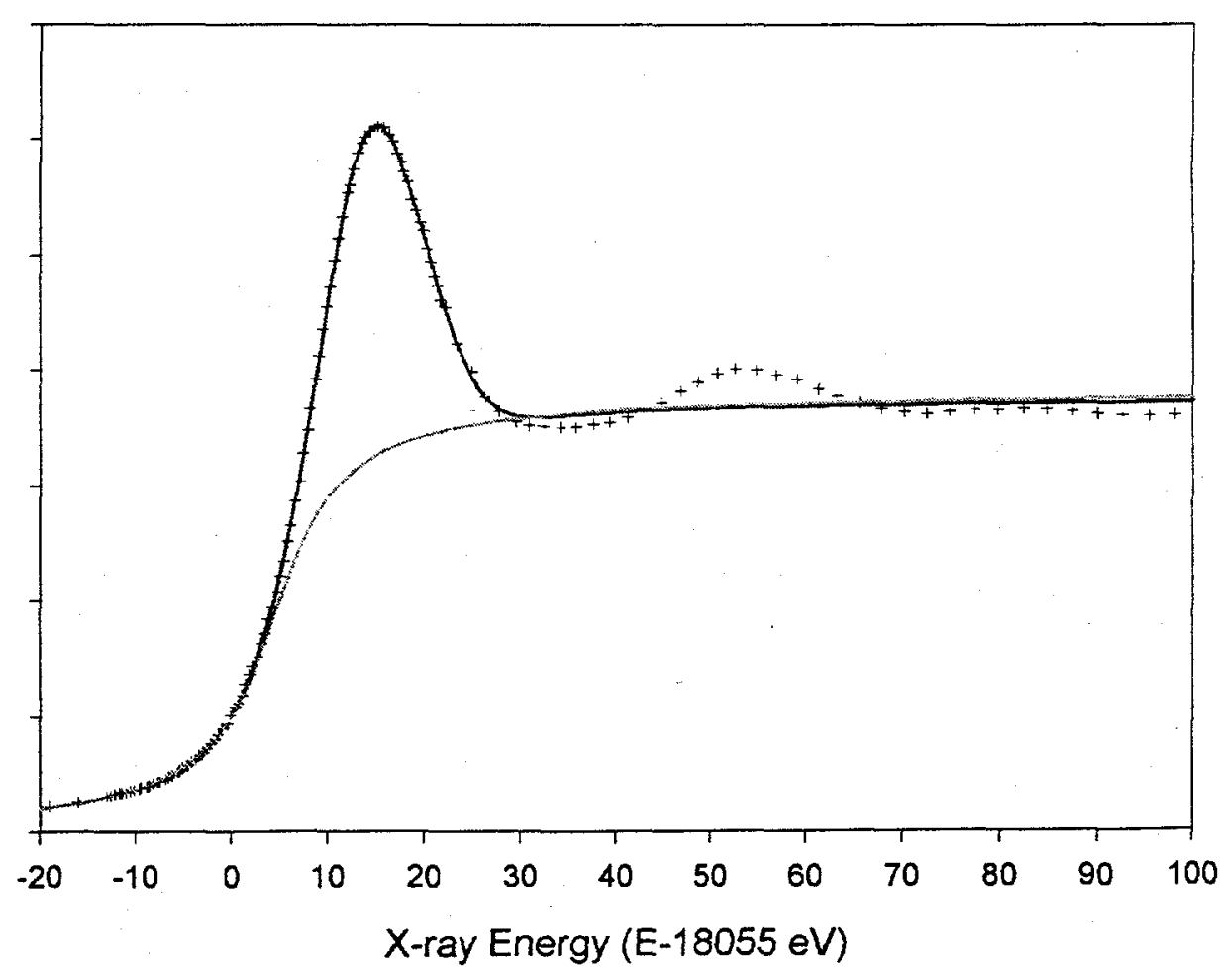

Figure 3.The plutonium XANES from the pyrochlore ceramic has an oxidation state very near $\mathrm{Pu}(\mathrm{IV})$, by comparison with $\mathrm{PuO}_{2}$ reference data [4]. Shown is the data (hatches) with the fit generated as a sum (dark gray line) of a Lorentzian and hyperbolic tangent (light gray line) functions. For clarity, the Lorentzian function is not separately shown. 
The EXAFS functions (Figure 4) were nearly identical for the A0 and A9 samples, indicating a robust preferred crystal chemical environment for the plutonium in the ceramic. The real-space analysis of the A 0 ceramic in Figure 5 demonstrates a coordination environment for plutonium in the ceramic that is distinct from that in $\mathrm{PuO}_{2}$ (Figure 6). Notably, the first coordination shell of oxygen occurs at slightly reduced bond length, with a second shell coordination environment due to titanium. Residual scattering beyond the titanium shell at 3.59 $\AA$ is due to higher coordination shells, most likely heavy elements such as $\mathrm{Hf}, \mathrm{Gd}, \mathrm{U}$, or $\mathrm{Pu}$. The data were fitted over the $k$-space range from 3.0 to $10.5 \AA^{-1}$, using $k^{3}$ weighting. Fitted parameters $\mathrm{R}$ (bond length), $\mathrm{N}$ (coordination number), and $\sigma^{2}$ (Debye-Waller and static disorder parameter) obtained are listed in Table 2 . The values of the bond lengths in Table 2 differ from the apparent bond lengths in Figures 5 and 6 owing to a scattering phase shift. The phase shift was incorporated into the FEFFIT fitting of Table 2 but not in the Fourier transform displayed in Figures 5 and 6 . The obtained structural information is consistent with $\mathrm{Pu}$ occupying the $\mathrm{Ca}$ site in the pyrochlore structure. Note that for the ideal (cubic) pyrochlore structure, the calcium and zirconium (hafnium) sites are indistinct, in contrast with previous studies on zirconolite [5].

Table 2. Coordination results from $\mathrm{Pu}-\mathrm{L}_{\mathrm{III}}$ EXAFS analysis

\begin{tabular}{ccccccc}
\hline Sample & $\mathrm{R} 1(\AA)$ & $\mathrm{N} 1(\mathrm{O})$ & $\sigma^{2}$ & $\mathrm{R} 2(\AA)$ & $\mathrm{N} 2(\mathrm{Ti})$ & $\sigma^{2}$ \\
A0 & $2.30 \pm 0.05$ & $9.5 \pm 2.2$ & $0.020 \pm 0.004$ & $3.59 \pm 0.02$ & $9.0 \pm 1.5$ & $0.013 \pm 0.004$ \\
& & & & & & \\
A9 & $2.30 \pm 0.05$ & $10.3 \pm 2.5$ & $0.022 \pm 0.004$ & $3.59 \pm 0.02$ & $13.0 \pm 2.5$ & $0.018 \pm 0.004$
\end{tabular}

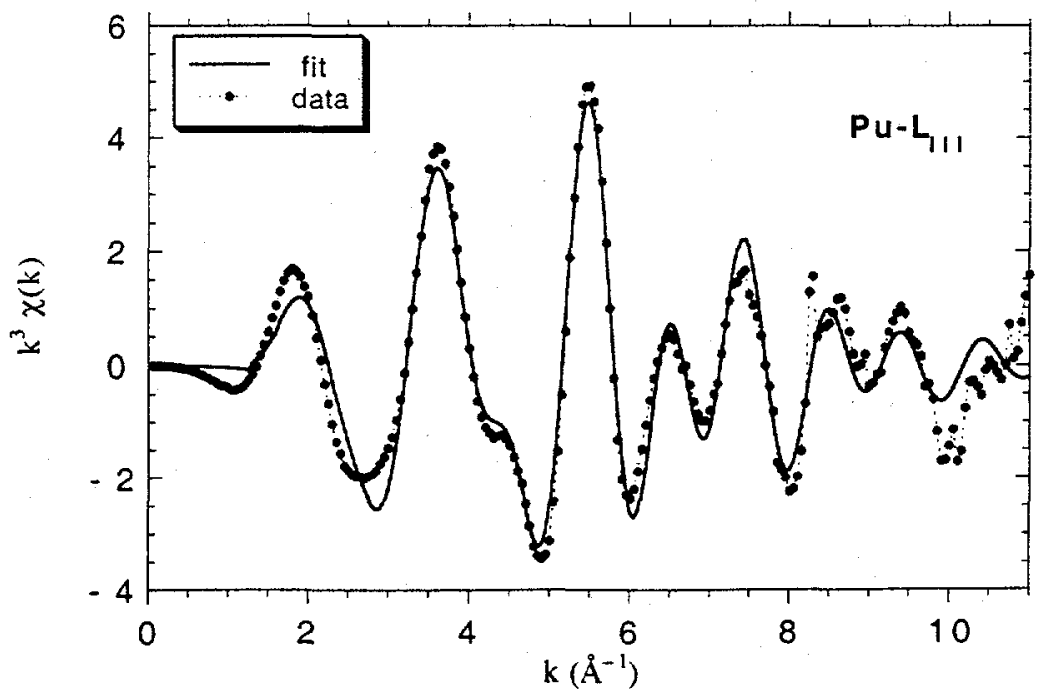

Figure 4. Plutonium $\mathrm{L}_{\text {III }}$ EXAFS data (dotted line) with fit obtained from $F E F F 8$ (solid line) for the $\mathrm{A} 0$ sample. 


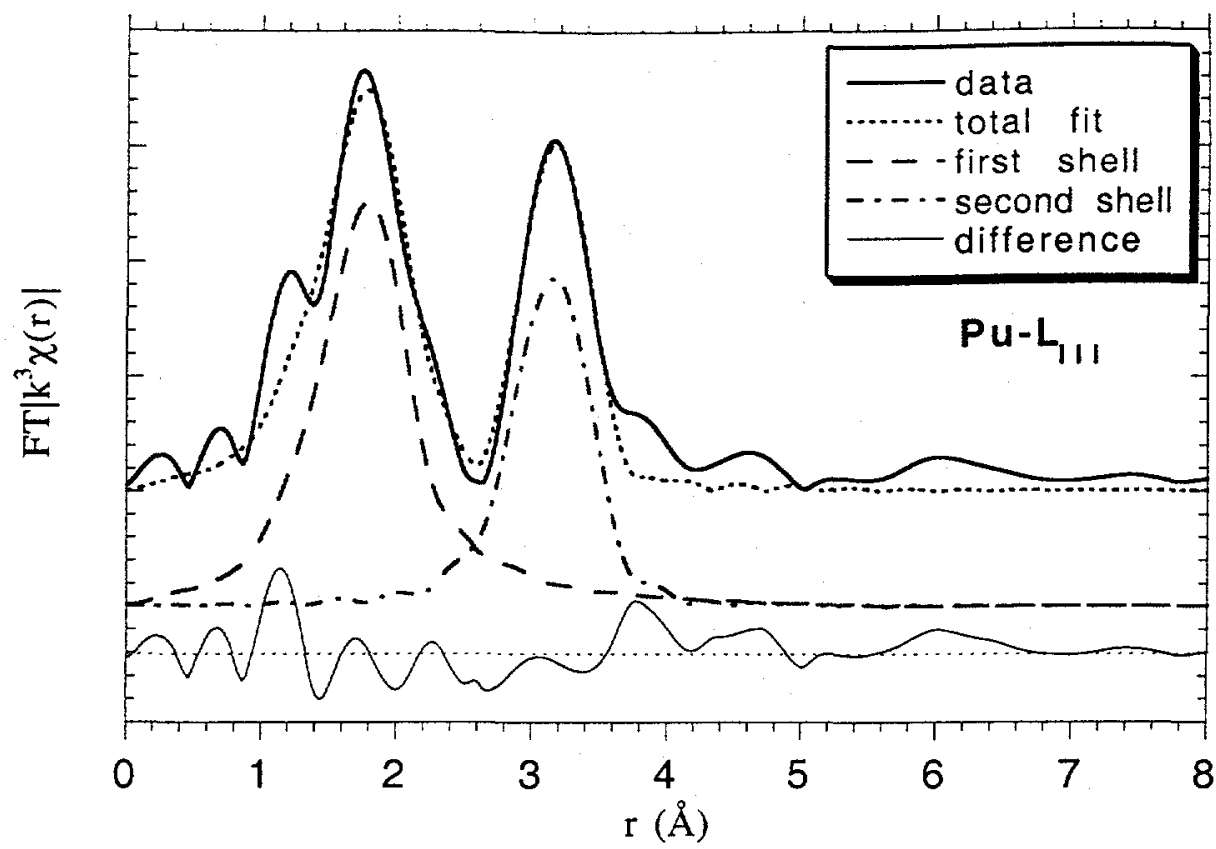

Figure 5. Plutonium EXAFS radial function with fits for the A0 sample. The residual contains substantial structure beyond the titanium shell originating from coordination by heavy elements.

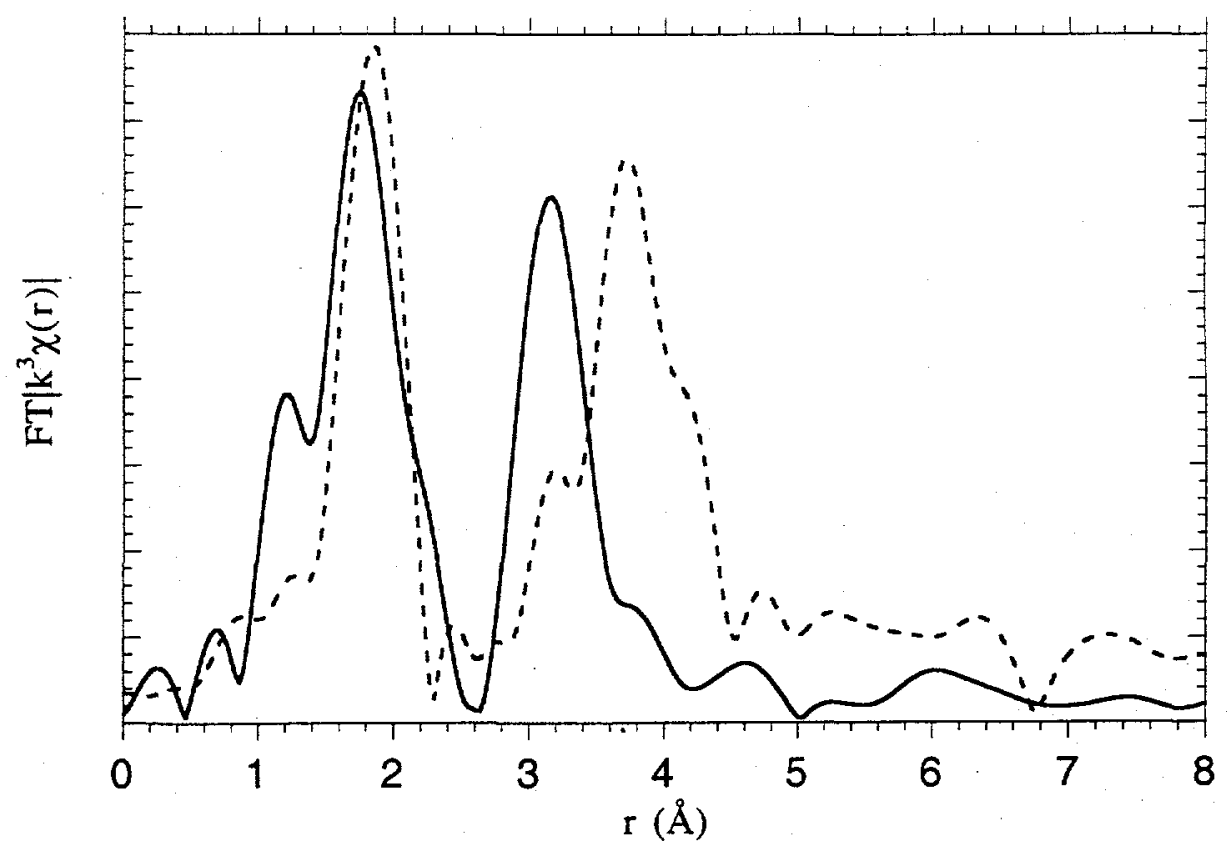

Figure 6. The EXAFS of the ceramic (solid line) shows a local structure distinct from that of $\mathrm{PuO}_{2}$ [4] (dashed line). 


\section{CONCLUSIONS}

We have demonstrated the use of EXAFS/XANES to establish the crystal chemistry of plutonium and cerium in a prototype immobilization ceramic. Plutonium is found to be nearly all $\mathrm{Pu}(\mathrm{IV})$ and to occupy a calcium site in the pyrochlore structure. Cerium, when substituted for both plutonium and uranium in the ceramic, has a formal valence of approximately 3.7 , as determined by a fit of the Ce- $L_{11}$ XANES with standards. The valence and coordination of uranium in these ceramics will be the topic of a future study.

\section{REFERENCES}

1. M. C. Hash, J. K. Basco, V. N. Zyryanov, and D. B. Chamberlain, Proceedings Paper for the 101st Am. Ceram. Soc. Annual Meeting, Indianapolis, 1999, Environmental Issues and Waste Management Technologies in the Ceramic and Nuclear Industries $V$ (in press, due spring 2000).

2. Available from FEFF Project, c/o Todd Case Department of Physics, Box 351560 University of Washington, Seattle WA, 98195, USA.

3. B. D. Begg, E. R. Vance, and G. R. Lumpkin, Mat. Res. Soc. Symp. Proc. 506, 79 (1998).

4. J. Kropf, D. T. Reed, and S. B. Aase, submitted to Journal of Synchrotron Radiation.

5. S. R. Conradson, Applied Spectroscopy 52 (7), 252A (1998).

This work was supported by the U.S. Department of Energy Office of Fissile Materials Disposition. Use of the Advanced Photon Source was supported by the U.S. Department of Energy, Basic Energy Sciences, Office of Energy Research (DOE-BES-OER), under Contract no. W-31-109-Eng-38. The MRCAT beamlines are supported by the member institutions and the U.S. DOE-BES-OER under contracts DE-FG02-94ER45525 and DE-FG02-96ER45589. 